\title{
Lighting and Marking of Agricultural Equipment on Highways: Summary of ASAE Standard S279.18
}

\author{
Serap Gorucu, Charles Brown, and Carol Lehtola ${ }^{2}$
}

\section{Introduction}

Agricultural vehicles on public roads can pose risks to their drivers and to drivers of other vehicles. Proper lighting and marking increase visibility of the farm equipment. This publication summarizes agricultural equipment lighting and marking standards for Extension agents, equipment dealers, and agricultural equipment operators.

\section{What are ASABE standards?}

The American Society of Agricultural and Biological Engineers (ASABE) is the professional society for those interested in engineering knowledge and technology for food, agriculture, and biological industries and resources.

The ASABE produces a series of standards-the ASABE Standards - that are based on experience and research. These standards are developed by volunteers representing industry, academia, government agencies, and concerned and interested citizens (ASABE 2021).

The ASABE's lighting and marking standard applies to all tractors, other self-propelled farm machinery, and towed machinery used for farm operations, which might be driven or towed on any road that is also accessible to the public. Self-propelled machines and towed machines are considered separately in the standard. For more details, see standard ASABE S390.6 (ASABE 2017).

Proper lighting and marking are essential for the safety of both equipment operators and other drivers. The reason for standard colors, placement, and types of lamps is to provide consistent information to drivers about the presence of farm vehicles and machinery on public roads, especially during low-visibility times (e.g., dusk, dawn, and night).

The following is a summary of ANSI/ASAE Standard S279.18, "Lighting and Marking of Agricultural Equipment on Highways." Consult the standard for exact details about acceptable lights and marking materials and their placement (ASABE 2019).

Local Extension agents and equipment dealers will be able to inform operators about local regulations that affect requirements of this standard (e.g., beacon-type warning lights). Local regulations take precedence over the requirements of the standard.

\section{Tractors and Self-Propelled Equipment}

The standard recommends features to light self-propelled equipment, which includes tractors. The standard requires

1. This document is ABE302, one of a series of the Department of Agricultural and Biological Engineering, UF/IFAS Extension. Original publication date September 2001. Revised January 2009 and February 2021. Visit the EDIS website at https://edis.ifas.ufl.edu for the currently supported version of this publication.

2. Serap Gorucu, assistant professor, Department of Agricultural and Biological Engineering; Charles Brown, writer and editor, research communications, University of Florida Transportation Institute Technology Transfer Center (UFTI-T2), UF Herbert Wertheim College of Engineering; and Carol Lehtola, former emeritus faculty, Department of Agricultural and Biological Engineering; UF/IFAS Extension, Gainesville, FL 32611.

The Institute of Food and Agricultural Sciences (IFAS) is an Equal Opportunity Institution authorized to provide research, educational information and other services

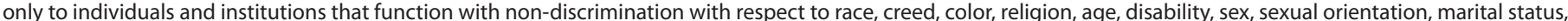

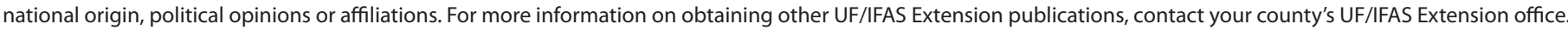
U.S. Department of Agriculture, UF/IFAS Extension Service, University of Florida, IFAS, Florida A \& M University Cooperative Extension Program, and Boards of County Commissioners Cooperating. Nick T. Place, dean for UF/IFAS Extension. 
that lighting and marking meet both placement and visibility standards. This document summarizes placement and a few operational details only. To ensure proper visibility, use fixtures and materials labeled by the manufacturer as meeting ASABE standards. Extension agents and equipment dealers will be able to assist operators with selecting proper equipment.

\section{Lighting for Tractors and Self-Propelled Equipment that Travel at 25 Miles per Hour or Less}

Tractors and self-propelled equipment must carry (1) headlamps, (2) tail lamps, (3) warning lamps, and (4) turn indicators. For proper lateral and vertical placement of lights or lamps on tractors and self-propelled equipment, the recommended features are:

Headlamps: At least two headlamps should be mounted at the same height. These should be spaced as far apart as practical and equidistant from the centerline ("centered laterally"). The standard also defines the brightness of headlamps in terms of the intensity of their beams at 25 feet.

Work lamps and general service lamps: Forward-facing work lamps or general service lamps should be aimed downward to provide illumination close to the equipment. During highway travel, rear-facing work lamps or general service lamps must be turned off.

Tail lamps: Two red tail lamps should be mounted symmetrically at the rear of the vehicle (i.e., at the same height and at the same distance from the vehicle centerline). Tail lamps should be mounted between 16 inches and 10 feet above the ground. Tail lamps should be equally spaced from the vehicle centerline, as widely as practical but no farther apart than 10 feet (5 feet on either side).

Warning lamps: At least two amber flashing warning lights should be mounted as widely spaced as practical and should be visible from both front and rear. The lamps should flash in unison at 60 to 85 flashes per minute, and they should be positioned between 16 inches and 12 feet high from the ground.

Rotating or strobe beacons may also be used. Additional requirements apply to machines more than 12 feet wide. See the standard for details.

Turn indicators: In addition to red tail lights, the equipment should carry turn indicators. To signal a turn, both the turn indicator and the warning light on the appropriate side of the equipment should flash.

Red or amber turn signals should be placed using the same guidance that applies to tail lamps. The correct turn indicator should flash with the warning light on the same side. The opposite turn indicator can remain off or become brighter, but it must not flash.

When a turn indicator is on, the warning light on the side of the flashing turn signal should flash faster (i.e., at least 20 more flashes per minute than normal, up to 125 flashes per minute). The warning light on the side opposite the direction of the turn should burn steady (not flash).

Equipment that carries stop lights as described below do not need additional turn indicators, regardless of speed.

\section{Lighting for Tractors and Self-Propelled Equipment That Can Travel at More Than 25 Miles per Hour}

Headlamps, tail lights, warning lights, and turn indicators: Equipment that can travel at speeds greater than 25 miles per hour should carry the same lights and markers as equipment that travels at 25 miles per hour or less.

Turn indicators: Equipment with stop lights that also serve as turn indicators do not need additional turn indicators, regardless of speed.

Stop lights: Equipment that can travel at speeds greater than 25 miles per hour should also be equipped with two rear-facing stop lights. The stop lamps should activate when the machine deceleration rate is greater than 2 miles per hour per second in control braking mode.

If the machine is less than 4 feet wide, only one lamp is required, and it should be mounted in the center of the rear of the machine.

\section{Marking for Tractors and Self-Propelled Equipment}

Tractors and self-propelled equipment should be marked with both nonlighted reflectors ("retroreflective devices") and retroreflective tape ("conspicuity material").

Retroreflective devices: At least two red retroreflective devices shall be visible to the rear at night at distances up to 1,000 feet as viewed by a vehicle following directly behind using low-beam headlamps. The reflectors should be mounted to mark the extreme right and left points of the 
equipment. If the tail lights incorporate these reflectors and are placed to indicate the rightmost and leftmost points of the equipment, then they fulfill this part of the standard.

Conspicuity material: For machines over 12 feet wide, conspicuity material must be supplied that makes the equipment visible from the front and the rear.

Front-facing material should be at least two strips of yellow and retroreflective material. For rear-facing material, use both red retroreflective material and red, nonreflective, fluorescent material. These are the specific colors defined in the standard. The material should be as horizontal (level) as possible. Rear-facing and front-facing material should be aligned. Apply sufficient conspicuity material so that there is no gap between markings greater than 6 feet. The material should be placed so that it extends within 25 inches of the rightmost and leftmost points of the equipment.

SMV: One standard Slow Moving Vehicle (SMV) emblem must be installed on the machine.

Speed Identification Sign (SIS): When on public roads, vehicles that can travel between 25 and 40 miles per hour require an SIS. For vehicles that travel below 25 miles an hour, the SIS is optional. For vehicles that travel above 40 miles an hour, the SIS is prohibited.

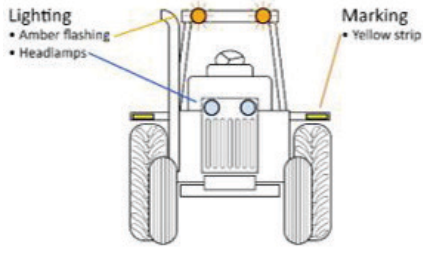

a) front view

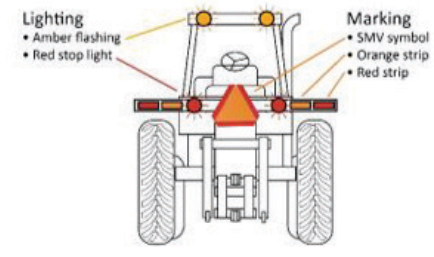

b) rear view
Figure 1. Lighting and marking a tractor.

Credits: Charles Brown, University of Florida

\section{Electrical Connector-Tractors and Self- Propelled Vehicles}

One seven-terminal receptacle conforming to SAE J560 shall be mounted at the rear of the machine in a region defined in the standard. The receptacle must be placed vertically at least 12 inches above the drawbar and no higher than 50 inches above the drawbar. The region extends 36 inches toward the front from the axle and 10 inches on either side of the vehicle centerline.

Tractors and self-propelled machines not primarily used with agricultural implements, such as garden tractors or high-clearance sprayers, are excluded.

\section{Non-Self-Propelled Equipment}

Tractors and self-propelled equipment should be marked with both nonlighted reflectors ("retroreflective devices" in the standard) and retroreflective tape ("conspicuity material" in the standard).

\section{Lighting for Non-Self-Propelled Equipment}

Lamps required for non-self-propelled equipment should be connected to the seven-terminal plug described above.

\section{LIGHTING EQUIPMENT THAT OBSCURES TOWING VEHICLE LIGHTS}

Equipment to the rear or the front of the towing vehicle that obscures any flashing warning lamp, tail lamp, extremity lamp, or stop lamp on the towing vehicle should be fitted with lights that match the obscured lamp(s). This does not include rotating beacons or strobe beacons.

Stop lamps: Stop lamps are required on towed or rearmounted equipment only when that equipment has a designated speed of 25 miles per hour or more.

Tail lamps: If the tail lamps on the towing vehicle are obscured, then at least two red tail lamps should be mounted symmetrically to the rear of the equipment. The tail lamps should be positioned between 2 feet and 5 feet to either side of the vehicle centerline and between 16 inches and 10 feet from the ground.

On equipment less than 6 feet 9 inches wide, space the tail lamps as widely as possible and between 16 inches and 10 feet from the ground.

Warning lamps: If the rear flashing warning lamps are obscured, supply at least two amber flashing warning lamps that are visible from the rear. If the flashing warning lamps are obscured from the front, supply at least two amber flashing warning lamps that are visible from the front. The equipment-mounted flashing lights should flash in unison with the towing vehicle's flashing warning lights.

Place the lamps symmetrically, and space them as widely as possible at the same height, preferably between 16 inches and 10 feet; however, they may be mounted between 16 inches and 12 feet if required by machine design.

For equipment that extends only to the right or left and obscures only one flashing warning light, only one flashing warning light must be placed on the mounted or towed 
equipment. Place it laterally within 16 inches of the farthest point on the equipment from the vehicle centerline.

Turn indicators: If the rear turn indicators on the towing vehicle are obscured, then provide rear turn indicators on the towed or rear-mounted equipment. Similarly, if the front turn indicators on the towing vehicle are obscured, provide front turn indicators on the front-mounted equipment.

\section{LIGHTING FOR EQUIPMENT WIDTH}

The following lighting requirements apply to mounted or towed equipment that is more than 12 feet wide or extends more than 6 feet from the towing vehicle centerline and beyond either the leftmost or rightmost point of the towing vehicle.

Warning lamps: Supply at least two amber flashing warning lamps that are visible from the front and the rear. The equipment-mounted flashing lights should flash in unison with the towing vehicle's flashing warning lights.

Place the lamps symmetrically, and space them as widely as possible within 16 inches of the leftmost and rightmost points of the equipment. Place the lamps between 16 inches and 10 feet from the ground, and up to 12 feet if required by machine design.

For equipment that extends only to the right or left and obscures only one flashing warning light, only one flashing warning light must be placed on the mounted or towed equipment. Place it laterally within 16 inches of the farthest point on the equipment from the vehicle centerline.

Tail lamps: Supply at least two red tail lamps mounted symmetrically to the rear of the equipment and between 16 inches and 10 feet from the ground.

The tail lamps should be positioned between 2 feet and 5 feet on either side of the vehicle centerline and between 16 inches and 10 feet from the ground. If the towed or rearmounted equipment does not obscure the towing vehicle's tail lamps, the tail lamps may be placed more than 5 feet from the vehicle centerline.

On equipment less than 6 feet 9 inches wide, space the tail lamps as widely as possible.

On equipment less than 4 feet wide at its rearmost, only one tail lamp is required.
Turn indicators: Towed or rear-mounted equipment should carry turn indicators as previously described. On equipment less than 4 feet wide at its rearmost, turn indicators are not needed.

\section{LIGHTING FOR EQUIPMENT LENGTH}

For equipment that extends more than 25 feet to the rear beyond the hitch point, refer to the "Lighting for Equipment Width" section above.

\section{LIGHTING FOR EQUIPMENT SPEED}

For equipment that can travel at speeds greater than 25 miles per hour, refer to the "Lighting for Tractors and Self-Propelled Equipment That Can Travel at More Than 25 Miles per Hour" section above.

\section{Marking for Non-Self-Propelled Equipment}

SMV: A least one SMV emblem must be mounted on interchangeable towed machinery and trailers. If the towing vehicle and towed equipment can travel faster than 40 miles per hour, the SMV emblem must be removed or covered.

If the towed equipment obscures the SMV emblem on the towing vehicle or extends more than 16 feet 5 inches beyond the hitch point, a standard SMV emblem shall be mounted on the towed equipment.

SIS: Interchangeable towed machinery and trailers shall carry at least one rear-facing standard SIS that states the maximum ground speed.

Speed label on implement: The front of the towed implement must be provided with information for the operator about the maximum towing speed of the implement. A forward-facing standard SIS is preferred.

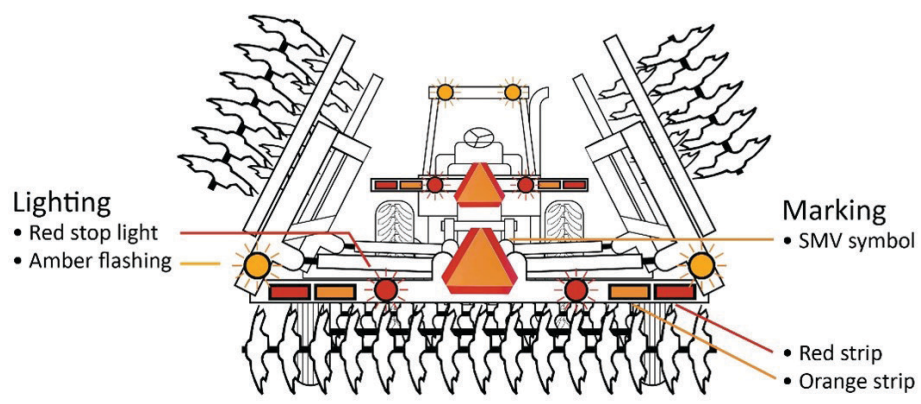

Figure 2. Lighting and marking for towed implement. Credits: Charles Brown, University of Florida 


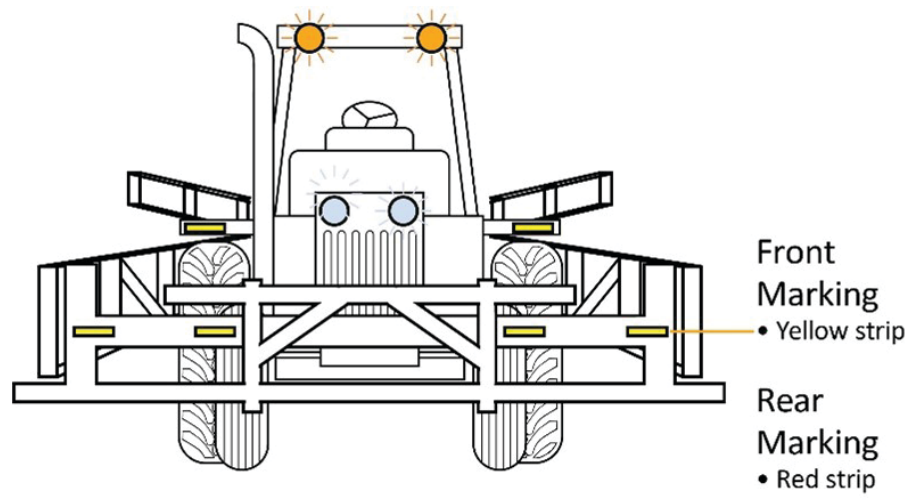

Figure 3. Lighting and marking for front-mounted implement. Credits: Charles Brown, University of Florida

\section{References}

American Society of Agricultural and Biological Engineers (ASABE). 2019. ANSI/ASAE Standard S279.18: Lighting and Marking of Agricultural Equipment on Highways. St. Joseph, MI: ASABE. https://elibrary.asabe.org/abstract. asp?aid $=50939 \& \mathrm{t}=2$

American Society of Agricultural and Biological Engineers (ASABE). 2017. ASAE Standard S390.6: Tractors and Machinery for Agriculture and Forestry-Basic Types-Vocabulary. St. Joseph, MI: ASABE.

American Society of Agricultural and Biological Engineers (ASABE). 2021. "National Standards." Accessed on January 22, 2021. https://www.asabe.org/Publications-Standards/ Standards-Development/National-Standards 
Table 1. Marking towed or rear-mounted equipment.

\begin{tabular}{|c|c|c|}
\hline Equipment & Yellow Front Marking & Red Rear Marking \\
\hline $\begin{array}{l}\text { Width: Extends more than } \\
4 \text { feet from towing vehicle } \\
\text { centerline }\end{array}$ & $\begin{array}{l}\text { - At least one strip of yellow retroreflective } \\
\text { material } \\
\text { - Visible to the front } \\
\text { - Placed to show the leftmost point of the } \\
\text { equipment }\end{array}$ & $\begin{array}{l}\text { - At least two strips of red retroreflective material } \\
\text { - Visible to the rear } \\
\text { - Placed to show the leftmost and rightmost points of the } \\
\text { equipment }\end{array}$ \\
\hline $\begin{array}{l}\text { Width: More than } 12 \text { feet } \\
\text { wide or extends more than } \\
6 \text { feet to either side of the } \\
\text { towing vehicle centerline }\end{array}$ & $\begin{array}{l}\text { - At least two strips of yellow retroreflective } \\
\text { material } \\
\text { - Visible from the front } \\
\text { - Placed to show the leftmost and rightmost } \\
\text { points of the equipment } \\
\text { - One edge of a marking strip must be } \\
\text { within } 16 \text { inches of the outermost point of } \\
\text { the equipment it marks. }\end{array}$ & $\begin{array}{l}\text { - Strips of red retroreflective material and nonreflective red- } \\
\text { orange fluorescent material } \\
\text { - Visible from the rear } \\
\text { - Placed to show the leftmost and rightmost points of the } \\
\text { equipment } \\
\text { - Strips should be as horizontal, aligned, and evenly spaced as } \\
\text { possible. } \\
\text { - Place strips so that no gap between strips exceeds } 6 \text { feet. } \\
\text { - One edge of a retroreflective marking strip must be within } \\
16 \text { inches of the outermost point of the equipment it marks. } \\
\text { - One edge of a nonreflective fluorescent marking strip } \\
\text { must be within } 25 \text { inches of the outermost point of the } \\
\text { equipment it marks. }\end{array}$ \\
\hline $\begin{array}{l}\text { Length: Extends more than } 4 \\
\text { feet from hitch point }\end{array}$ & & $\begin{array}{l}\text { - At least two red retroreflective devices } \\
\text { Visible to the rear } \\
\text { - Placed to show the leftmost and rightmost points of the } \\
\text { equipment }\end{array}$ \\
\hline $\begin{array}{l}\text { Length: Including } \\
\text { combinations, extends more } \\
\text { than } 16 \text { feet from hitch point }\end{array}$ & $\begin{array}{l}\text { - Must have yellow retroreflective material } \\
\text { - Visible from the right and left sides } \\
\text { - Space the strips no more than } 16 \text { feet } \\
\text { apart. } \\
\text { - Mark the rearmost point of the side of the } \\
\text { towed equipment. }\end{array}$ & \\
\hline
\end{tabular}

Table 2. Marking front-mounted equipment.

\begin{tabular}{|c|c|c|}
\hline Equipment & Yellow Front Marking & Red Rear Marking \\
\hline $\begin{array}{l}\text { More than } 12 \text { feet wide or } \\
\text { extends more than } 6 \text { feet } \\
\text { to either side of the towing } \\
\text { vehicle centerline }\end{array}$ & $\begin{array}{l}\text { - At least two strips of yellow retroreflective } \\
\text { material } \\
\text { - Visible from the front } \\
\text { - Placed to show the leftmost and rightmost } \\
\text { points of the equipment } \\
\text { - One edge of a marking strip must be within } \\
16 \text { inches of the outermost point of the } \\
\text { equipment it marks. }\end{array}$ & $\begin{array}{l}\text { - At least red retroreflective material and nonreflective red- } \\
\text { orange fluorescent material } \\
\text { - Visible from the rear } \\
\text { - Placed to show the leftmost and rightmost points of the } \\
\text { equipment } \\
\text { - Placed as horizontal, aligned, and evenly spaced as } \\
\text { possible } \\
\text { - Spaced so that no gap between strips exceeds } 6 \text { feet } \\
\text { - No reflective material is required on front-mounted } \\
\text { equipment for a distance of } 4 \text { feet on either side of the } \\
\text { propelling machine centerline. } \\
\text { - One edge of a retroreflective marking strip must be within } \\
16 \text { inches of the outermost point of the equipment it } \\
\text { marks. } \\
\text { One edge of a nonreflective fluorescent marking strip } \\
\text { must be within } 25 \text { inches of the outermost point of the } \\
\text { equipment it marks. }\end{array}$ \\
\hline
\end{tabular}

